\title{
Physical Attractiveness as a Mediator of the Impact of Early Pubertal Changes for Girls
}

\author{
David F, Zakin,' Dale A. Blyth, ${ }^{2}$ and Roberta G. Simmons ${ }^{3}$
}

Received May 19, 1984; accepted for publication July 25, 1984

The present study examined the effects of early pubertal development and physical attractiveness on the popularity, body image, and self-esteem of over 200 sixth-grade girls. Two rival hypotheses were explored. The first suggests that physically attractive girls, because of their more favorable social environment, will exhibit fewer psychosocial difficulties than unattractive girls during pubertal development. The second hypothesis argues that attractive girls will exhibit greater difficulty during pubertal transition because their selfimage is more intimately connected with their physical appearance. Although there were no significant interactions between attractiveness and pubertal development for either popularity or body image, the second hypothesis was supported with respect to self-esteem. Specifically, developing attractive girls exhibited lower self-esteem than their unattractive counterparts. The results are discussed in terms of the relative vulnerability to bodily changes of girls differing in physical attractiveness.

Support for this work was provided by NIMH Grant 2 R01 MH-30739 and the William T. Grant Foundation.

'Department of Psychology, University of Michigan. Received his M.A. in clinical child psychology from the Ohio State University. Main interests are the psychological concomitants of physical appearance and developmental aspects of the body image.

2Department of Psychology, Ohio State University. Received his Ph.D. in sociology from the University of Minnesota. Current interests include social relationships in adolescence, consequences and correlates of physical maturation, and effects of transitions in early adolescence.

${ }^{3}$ Department of Sociology, University of Minnesota. Received her Ph.D. in sociology from Columbia University. Current interests include gender differences in adolescence, the impact of transitions throughout the life span, and the psychosocial impact of organ donation. 


\section{INTRODUCTION}

The body as a social stimulus has become an increasingly popular area of research in recent years. In part this reflects the trend away from describing individual behavior in terms of global traits and toward emphasizing the person-situation interaction (Bowers, 1973; Endler and Magnusson, 1976). One constant in every person-situation interaction is the individual's physical appearance. Popular cliches such as "you can't judge a book by its cover" to the contrary, people tend to make personality inferences and attributions on the basis of physical appearance (Miller, 1970).

Research concerning people's reactions toward the overweight and the physically unattractive demonstrates that physical appearance is a very powerful social stimulus. Numerous studies have shown that children's and adults' attitudes toward the obese are extremely negative (Lerner and Gellert, 1969; Staffieri, 1967), even across diverse social and ethnic backgrounds (Richardson and Royce, 1968). Staffieri (1967) found that children aged 6 through 10 years of age assign unfavorable and socially aggressive adjectives to pictures of obese individuals and assign them a low number of acceptance choices as determined by sociometric ratings.

Research into the role physical attractiveness plays in interpersonal relations demonstrates that a person's behavior is differentially affected by the physical attractiveness of the other person (Snyder et al., 1977; Berscheid and Walster, 1974). In the absence of other cues, people attribute the unattractive with unfavorable and the attractive with favorable personality characteristics (Dion et al., 1972). This "beautiful is good" bias is found in children as young as 4 years (Dion, 1973) and across different ethnic and racial groups (Langlois and Stephan, 1977). The literature also indicates that the unattractive are more easily forgotten (Kleck and Rubenstein, 1975), less likely to be offered assistance (Wilson, 1978), less socially rewarding (Barocas and Karoly, 1972), and more likely to be treated in a superficial manner (Pellegrini et al., 1978).

A still unexplored area of research, however, is whether individual differences in physical attractiveness translate into differences in the ability to adapt to the transition from childhood into adolescence. During this period of transition individuals are confronted with dramatic changes in their appearance including alterations in their body proportions, the formation of secondary sexual characteristics, and the development of a mature reproductive system. These physical changes necessarily precipitate changes in how the individual views his or her body. The development or maintenance of a healthy body image is thus one important aspect of adaptation during this transition period (Aldous, 1978; Havighurst, 1953). Also important is 
the individual's overall psychosocial adjustment to the new demands and challenges that accompany his or her new status as an early adolescent. Of the many challenges that the early adolescent faces, the establishment of strong peer relations and the maintenance of a healthy self-esteem have been considered two of the most important (Aldous, 1978; Havighurst, 1953; Simmons et al., 1979).

Research on the effects of pubertal transition has focused primarily on the relative influence of early versus late maturation on the individual's psychological and emotional adjustment (Petersen and Taylor, 1980; Clausen, 1975; Simmons et al., 1983; Blyth et al., 1981b). The literature indicates that early maturity appears to be consistently favorable for boys (Latham, 1951; Dwyer and Mayer, 1969; Simmons et al., 1979), presumably because of the status attributed to the adult male. For girls, however, early maturation appears to involve both positive and negative consequences. Garwood and Allen (1979) found that early-maturing girls experienced more problems than their undeveloped peers but that at the same time they possessed higher selfesteem. Simmons et al. $(1979,1983)$ have also demonstrated that the effect of early development can vary depending on the dimensions considered. Early maturing girls were found to have more negative body images, especially concerning their height and weight. At the same time, early development appeared to be an advantage in terms of independence and popularity with the opposite sex.

The present paper investigates whether the effects of early physical development for girls are mediated by the individual's level of physical attractiveness. In other words, is being physically attractive an asset or a liability for the early maturing girl? Two alternative hypotheses relevant to this question are what we shall refer to as the external-support hypothesis and the differential-vulnerability hypothesis. The external-support hypothesis argues that because the world is more hospitable for the attractive individual, the attractive girl has more resources at her disposal for coping with the transition into adolescence. For instance, attractive preadolescent and adolescent girls have been found to be more popular than unattractive girls with both their same- and their opposite-sex peers (Cavior and Dokecki, 1973; Lerner and Lerner, 1977). Moreover, the greater emphasis placed on physical appearance and contact with the opposite sex during the adolescent period (Simmons et al., 1979) should be to the advantage of the attractive girl. Research on college and adult females has found that attractive individuals are more successful in heterosexual encounters (Walster et al., 1966; Black, 1974) and that this success translates into greater happiness, psychological health, and self-esteem (Mathes and Kahn, 1975). The external-support hypothesis thus views the social relations of the attractive girl as a resource that will ease 
her transition into early adolescence. In contrast, the unattractive girl might be expected to be at a disadvantage because she will continue to compare unfavorably with her peers at a time when appearance becomes even more important. Lacking the social support which the attractive girl possesses, the unattractive girl is expected to react less favorably to pubertal onset.

The differential-vulnerability hypothesis, however, emphasizes the relative perspective of the attractive and unattractive girls. This hypothesis acknowledges that physically attractive girls generally become attractive adults (Adams, 1977) but argues that the individual can not recognize this while the changes are actually taking place. Instead, to the individual there is an element of risk or uncertainty involved in the physical changes that occur during pubescence. Attention must thus be focused on the individual's interpretation of the physical changes at the time that they occur. The attractive girl is accustomed to receiving preferential treatment because of her looks. Presumably her self-esteem is more tied up with her physical appearance. Consequently, when the attractive girl begins to experience the pubertal transition, the physical changes may be more traumatic and threatening for her because of the greater risk involved. The attractive girl's beautiful and highly valued features are now rapidly changing and she cannot know what the final outcome will be. During this time of physical metamorphosis the attractive child might thus be expected to be at a relative disadvantage. The unattractive child, on the other hand, may welcome the onset of puberty. From her perspective there is nothing to be lost as her body changes; the final version can only be an improvement. The popular myth of the ugly duckling that grows into a beautiful swan may offer her hope that she will develop into an attractive adolescent. Thus, the unattractive girl may cope relatively better with the changes her body undergoes during puberty.

The present study tests the applicability of the external-support and differential-vulnerability hypotheses. Specifically, it investigates whether being physically attractive is an asset or a liability for the early maturing girl who is undergoing pubertal changes. Three specific aspects of adjustment are assessed: perceived social acceptance, body image, and self-esteem. Both hypotheses predict that the attractive early maturer will perceive herself as more popular than her unattractive counterpart. However, the externalsupport hypothesis predicts that the attractive early-maturing girl's favorable peer relations will translate into a healthier body image and higher selfesteem. The differential-vulnerability hypothesis, on the other hand, predicts that the different interpretations that the attractive and unattractive attach to their body's changes will result in a more favorable body image and higher self-esteem for the unattractive early maturer. 


\section{METHODS}

\section{Subjects}

White girls in the sixth grade who were within 1 year of the age norm for their grade served as subjects for this study. The sample was drawn from a 5-year longitudinal study in the Milwaukee Public Schools designed to examine the influence of school environments and physical development on the social and psychological development of early adolescents. Eighteen schools in the Milwaukee School System were selected using a constrained, stratified, random sampling procedure. All sixth-grade students within each school were asked to take part in the study and over $80 \%$, or 924 , actually participated. The size of the full sample of white girls is 286 . [See Blyth et al. (1978) and Simmons et al. (1979) for a description of the methodology.]

\section{Measurement}

The social-psychological measures used in this article are based primarily on information obtained from private survey interviews with students in the sixth grade. Pubertal status was established by examining 5 years of data on each subject collected by specially trained nurses once or twice a year. It is a measure of when a girl reached menarche relative to her peers. Girls who developed "early" relative to their peers reached menarche prior to the beginning of seventh grade. They are referred to as "developing" during the sixth grade, although they may not have reached menarche by the time of the interview. The girls who developed later, relative to their peers, are referred to as "undeveloped" during the sixth grade. These girls reached menarche some time after entering seventh grade. Since menarche is a late sign of development, many of the developing girls will have passed their period of peak height growth and developed pubic hair and noticeable breasts. [See Blyth et al. (1981a) and Simmons et al. (1983) for more information on the measurement of pubertal onset.] Dividing the subjects into developing and undeveloped categories in this manner necessarily resulted in an unequal number of subjects in each group (78 and 150, respectively).

The attractiveness variable was based on an adult nurse's rating of two dimensions, perceived degree of thinness (using a five-point scale from fat to skinny) and perceived looks (using a five-point scale from ugly to very good-looking). Attractive subjects were defined as those whom observers rated as both above average in looks and average to thin in physique. Unat- 
tractive subjects were defined as those whom observers rated as both chubby in physique and below average in looks. Subjects whose ratings fell between the attractive and the unattractive groups were classified as average in attractiveness. Although the 1-year test-retest reliability of the two items $(0.64$ and 0.26 for thinness and looks, respectively) is somewhat low, we believe that the collapsing of categories and combination of variables provide a good approximation of general levels of attractiveness.

The social acceptance dimension consists of multiple-choice questions pertaining to the subject's perception of her same-sex and opposite-sex popularity. Subjects were asked how popular they felt they were with boys and with other girls on a four-point scale ranging from "not at all" to "very much."

The body-image dimension consists of three questions which directly evaluate the girl's satisfaction with her height, weight, and figure development using a four-point scale ranging from "not at all happy" to "very happy." Subjects were also asked to evaluate their looks on a four-point scale ranging from "not at all good-looking" to "very good-looking."

The self-esteem dimension consists of six items and is scored as a Guttman Scale. It is a modification of the Rosenberg Self-Esteem Scale specifically designed for children and young adolescents. [See Rosenberg and Simmons (1971) for further details concerning reliability and validity.] A high score on this scale indicates that the subject considers herself to be a person of worth. A low score on the scale indicates that the subject experiences some degree of self-rejection or dissatisfaction.

\section{RESULTS}

The data were analyzed using a $2 \times 3$ (Pubertal Status $\times$ Attractiveness) analysis of variance model.

\section{Perceived Social Acceptance}

The results for the two popularity measures indicate a strong effect for physical attractiveness (see Table I). Unattractive girls perceived themselves as less popular with boys $(M=2.00)$ than did either attractive girls $(M=$ 2.47) or girls average in attractiveness $(M=2.49)[F(2,193)=7.09, p<$ $0.001]$. Similarly, unattractive girls also perceived themselves as less popular with other girls $(M=2.86)$ than either the attractive girls $(M=3.21)$ or those average in attractiveness $(M=3.21)[F(2,217))=6.81, p<0.001]$. These results are consistent with the literature on the social and psychological in- 
Table I. Mean Perceived Social Acceptance with the Same and the Opposite Sex by Attractiveness and Pubertal Status

\begin{tabular}{|c|c|c|c|c|c|c|}
\hline \multirow{2}{*}{$\begin{array}{l}\text { Pubertal } \\
\text { status }\end{array}$} & \multicolumn{3}{|c|}{ Attractiveness } & \multicolumn{3}{|c|}{ Significance level ${ }^{a}$} \\
\hline & Low & Medium & High & PUB & ATT & INT \\
\hline \multicolumn{7}{|c|}{$\begin{array}{l}\text { Perceived acceptance with } \\
\text { same sex }\end{array}$} \\
\hline Undeveloped & 2.73 & 3.19 & 3.19 & ns & 0.001 & ns \\
\hline Developing & 2.95 & 3.28 & 3.25 & & & \\
\hline Total & 2.86 & 3.21 & 3.21 & & & \\
\hline \multicolumn{7}{|c|}{$\begin{array}{l}\text { Perceived acceptance with } \\
\text { opposite sex }\end{array}$} \\
\hline Undeveloped & 1.87 & 2.47 & 2.37 & ns & 0.001 & ns \\
\hline Developing & 2.11 & 2.55 & 2.61 & & & \\
\hline Total & 2.00 & 2.49 & 2.47 & & & \\
\hline \multicolumn{7}{|c|}{ Maximum number of cases ${ }^{b}$} \\
\hline Undeveloped & 17 & 91 & 42 & & & \\
\hline Developing & 20 & 32 & 26 & & & \\
\hline
\end{tabular}

a PUB, main effect for pubertal status; ATT, main effect for attractiveness; INT, interaction effect.

${ }^{b}$ The number of cases may vary slightly due to missing data on specific questions.

fluences of physical attractiveness. A significant pubertal effect was not found, although a previous analysis using this data set has reported that girls who had reached menarche by the time of the interview perceived themselves as significantly more popular with boys than girls who had not reached menarche (Simmons et al., 1983). The lack of a significant pubertal effect in the present analysis is due to the fact that some of the "early developers" considered in this paper will not have reached menarche by the time of the sixth-grade interview. In particular, Simmons et al. (1983) found that the actual onset of menarche prior to the interview was significantly associated with opposite-sex popularity in sixth grade, while the more general classification of being an early developer was not significantly related (although the direction of relationship was the same). More developed girls in both cases perceive themselves as more popular with boys.

\section{Body Image}

Turning now to the body image, we find that physical attractiveness again has a significant effect (see Table II). Unattractive girls perceived themselves as less good looking $[F(2,216)=4.21, p<0.02]$, less satisfied with their figure $[F(2,222)=7.24, p<0.001]$, and less satisfied with their weight $[F(2,224)=16.36, p<0.001]$ than either the attractive or average groups. In addition, a significant pubertal effect was found for satisfaction with 
Table 1I. Mean Satisfaction with Body Image by Attractiveness and Pubertal Status

\begin{tabular}{|c|c|c|c|c|c|c|}
\hline \multirow[b]{2}{*}{$\begin{array}{l}\text { Pubertal } \\
\text { dimension }\end{array}$} & \multicolumn{3}{|c|}{ Attractiveness } & \multicolumn{3}{|c|}{ Significance level ${ }^{\alpha}$} \\
\hline & Low & Medium & High & PUB & ATT & INT \\
\hline \multicolumn{7}{|c|}{ Satisfaction with height } \\
\hline Undeveloped & 3.47 & 3.08 & 3.17 & ns & ns & ns \\
\hline Developing & 3.30 & 3.09 & 3.12 & & & \\
\hline Total & 3.38 & 3.08 & 3.15 & & & \\
\hline \multicolumn{7}{|c|}{ Satisfaction with weight } \\
\hline Undeveloped & 1.82 & 2.84 & 2.81 & 0.016 & 0.000 & ns \\
\hline Developing & 1.75 & 2.39 & 2.62 & & & \\
\hline Total & 1.78 & 2.72 & 2.74 & & & \\
\hline \multicolumn{7}{|c|}{ Satisfaction with figure } \\
\hline Undeveloped & 2.06 & 2.76 & 2.88 & ns & 0.001 & ns \\
\hline Developing & 2.45 & 2.91 & 2.81 & & & \\
\hline Total & 2.27 & 2.80 & 2.85 & & & \\
\hline \multicolumn{7}{|l|}{ Evaluation of looks } \\
\hline Undeveloped & 2.25 & 2.75 & 2.71 & ns & 0.016 & ns \\
\hline Developing & 2.42 & 2.68 & 2.40 & & & \\
\hline Total & 2.34 & 2.73 & 2.59 & & & \\
\hline \multicolumn{7}{|c|}{ Maximum number of cases } \\
\hline Undeveloped & 17 & 91 & 42 & & & \\
\hline Developing & 20 & 32 & 26 & & & \\
\hline
\end{tabular}

${ }^{a}$ PUB, main effect for pubertal status; ATT, main effect for attractiveness; INT, interaction effect.

${ }^{b}$ The number of cases may vary slightly due to missing data on specific questions.

weight, with developing girls less satisfied with their weight than girls who were undeveloped $(M=2.30$ and 2.71 , respectively) $[F(1,224)=5.92, p$ $<0.02]$. The absence of a significant interaction, however, indicates that attractiveness does not mediate the effects of physical development on body image. Instead, the unattractive girl is likely to be less satisfied with various aspects of her body, regardless of pubertal changes.

\section{Self-Esteem}

The results for self-esteem presented in Table III indicate that unattractive subjects possess lower self-esteem than do average and attractive subjects $[F(2,226)=3.49, p<0.03]$. However, examined in isolation these results are misleading because of a significant pubertal status by attractiveness interaction for self-esteem $[F(2,225)=6.77, p<0.001]$. Undeveloped girls who were unattractive or average in appearance demonstrated lower self-esteem ( $M=1.94$ and 2.84 , respectively) than girls who were attractive $(M=3.86)$. Among developing girls, however, the unattractive and average subjects exhibited higher self-esteem ( $M=3.25$ and 3.47 , respectively) than the attractive subjects $(M=2.88)$. Pubertal development, therefore, meant 
Table III. Mean Self-Esteem by Attractiveness and Pubertal Status

\begin{tabular}{ccccccccc}
\hline & \multicolumn{3}{c}{ Attractiveness } & & \multicolumn{3}{c}{ Significance level } \\
\cline { 2 - 4 } & Low & Medium & High & & PUB & ATT & INT \\
\hline Self-esteem & & & & & & \\
Undeveloped & 1.94 & 2.84 & 3.86 & ns & 0.03 & 0.001 \\
Developing & 3.25 & 3.47 & 2.88 & & & \\
$\quad$ Total & 2.65 & 3.00 & 3.49 & & & \\
Number of cases & & & & & & & \\
Undeveloped & 17 & 91 & 42 & & & \\
Developing & 20 & 32 & 26 & & & \\
\hline
\end{tabular}

${ }^{a}$ PUB, main effects for pubertal status; ATT, main effects for attractiveness; INT, interaction effects.

a loss in self-esteem for attractive girls and a boost in self-esteem for average and unattractive girls. The results indicate that physical attractiveness does mediate the effects of pubertal development on self-esteem. Specifically, pubertal development is beneficial for the unattractive girl's self-esteem and harmful for the attractive girl's self-esteem. These results support the differential-vulnerability hypothesis' prediction that pubertal development is less traumatic and perhaps even beneficial for the unattractive girl.

\section{DISCUSSION}

This study examined the question of whether physical attractiveness influences a girl's psychological and social adjustment to the transition into puberty. The issue was explored with two alternate hypotheses in mind. Results indicate that in the important area of self-esteem, the level of physical attractiveness may indeed have an influence on an individual's ability to adjust. The findings favor the differential-vulnerability hypothesis, which maintains that the nature of the reaction to pubertal development is a function of the perceived risk that physical change entails. Specifically, girls who have relatively more to lose from changes in their appearance (i.e., the attractive girls) react negatively to the onset of puberty. Girls who have the least to lose from such changes in their physical appearance (i.e., the unattractive girls) react more favorably to pubertal onset.

The findings also underline the importance of emphasizing the individual's own interpretation of his or her circumstances, rather than concentrating primarily on the view of others. Regardless of pubertal status, unattractive girls perceived themselves as less popular with others than did attractive girls. This result is consistent with the research on physical attractiveness, which indicates that attractive individuals are better treated and more popular than the unattractive. From this finding one might surmise that the unattractive 
girl's social disadvantages would impede her psychological adjustment to physical change. The same physical change might be expected to be less threatening to the attractive girl because she can evoke more support from her environment. However, it appears that it is a girl's interpretation of the situation from her unique perspective, rather than merely the social support she has customarily elicited from her environment, which influences her response to bodily change. On the one hand, those who perceive themselves as having more to lose from a change in their appearance react in a less favorable manner. This is reflected in the lower self-esteem for attractive girls who have begun to develop physically as compared to their undeveloped counterparts. On the other hand, those who perceive themselves as having something to gain react favorably to pubertal changes. Unattractive girls who are physically developing show higher self-esteem than those who are undeveloped. In fact, among developing girls the unattractive exhibit higher selfesteem than the attractive. Further support for this hypothesis comes from the fact that developing attractive girls give lower evaluations of their overall looks than undeveloped attractive girls, while developing unattractive girls give higher evaluations of their looks than unattractive girls who have not yet begun to develop. In fact, developing unattractive and attractive girls give similar evaluations of their overall looks.

An alternative explanation for the present findings is that developing attractive girls face a different set of social circumstances than do their unattractive counterparts. The developing girl's bodily changes, including breast development, alter the nature of her interactions with the opposite sex, imbuing them with more sexual connotations. Simmons et al. (1979) found that early involvement with boys is associated with problems in self-esteem and school adjustment. Specifically, girls who date early were found to have lower self-esteem and more academic and behavioral problems at school. The findings were explained in terms of these young girls not being emotionally mature enough to handle the more adult demands and pressures that dating entails. Physically attractive girls, due to their greater appeal, are particularly likely to draw such attention from boys. Heterosexual contact, casual or not, may serve to confront the developing attractive girl with the actual and long-term implications of her body's development. In other words, because of the reactions her physical appearance elicits from others, she may be more aware of the fact that she has indeed made a transition into a new role. This realization combined with an increase in emotional demands may precipitate a change in her self-image, which is reflected in lower self-esteem. Support for this view comes from the fact that developing attractive girls continue to be more satisfied with certain aspects of their bodies than are developing unattractive girls. This finding suggests that developing attractive girls are still aware of their physical attractiveness. Thus, the developing 
attractive girl's lower self-esteem may not be due to concern over losing a socially desirable characteristic but rather to a greater awareness that puberty means a change in status and roles. This alternative interpretation, however, does not account for why the developing unattractive girls demonstrated significantly higher self-esteem than their undeveloped counterparts.

In short, this study reveals that puberty may have different connotations for girls differing in physical attractiveness. Interestingly, it is the unattractive girl who reacts more favorably to pubertal changes in terms of self-esteem. Future research might concentrate on the developing unattractive girl's specific feelings concerning her pubertal development. For example, does the unattractive girl perceive her body's changes as a magical event that may transform her into a "beautiful swan"? In any case, developmental change appears to be interpreted differently by the previously advantaged and the previously disadvantaged. Thus, possessing a highly valued characteristic during periods of change does not necessarily protect an individual from psychological difficulties. Instead, the change may actually increase the person's vulnerability to threats to his or her self-esteem.

\section{REFERENCES}

Adams, G. (1977). Physical attractiveness research: Toward a developmental social psychology of beauty. Hum. Dev. 20: 217-239.

Aldous, J. (1978). Family Careers: Developmental Change in Families, Wiley, New York.

Barocas, R., and Karoly, P. (1972). Effects of physical appearance on social responsiveness. Psychol. Rep. 31: 495-500.

Berscheid, E., and Walster, E. (1974). Physical attractiveness. In Berkowitz (ed.), Advances in Experimental Social Psychology, Academic Press, New York.

Black, H. (1974). Physical attractiveness and similarity of attitude in interpersonal attraction. Psychol. Rep. 35: 403-406.

Blyth, D. A., Simmons, R., and Bush, D. (1978). The transition into early adolescence: A longitudinal comparison of youth in two educational contexts. Sociol. Educ. 51: 149-162.

Blyth, D. A., Bulcroft, R., and Simmons, R. G. (1981a). The impact of puberty on adolescents: A longitudinal study. Presentation at the Annual Meeting of the American Psychological Association, Los Angeles.

Blyth, D. A., Simmons, R. G., Bulcroft, R., Felt, D., Van Cleave, E. F., and Bush, D. M. (1981b). The effects of physical development on self-image and satisfaction with bodyimage for early adolescent males. In Simmons, R. G. (ed.), Research in Community and Mental Health, JAI Press, Greenwich, Conn., Vol. 2, pp. 43-73.

Bowers, K. (1973). Situationism in psychology: An analysis and a critique. Psychol, Rev. 80: 307-336.

Cavior, N., and Dokecki, P. (1973). Physical attractiveness, perceived attitude similarity, and academic achievement as contributors to interpersonal attraction among adolescents. Dev. Psychol. 9: 4-54.

Clausen, J. A. (1975). The social meaning of differential physical and sexual maturation. In Dragastin, S. E., and Elder, G. H., Jr. (eds.), Adolescence in the Life Cycle: Psychological Change and Social Context, Hemisphere, Washington, D.C.

Dion, K. (1973). Young children's stereotyping of facial attractiveness. Dev. Psychol. : 183-188. 
Dion, K., Berscheid, E., and Walster, E. (1972). What is beautiful is good. J. Personal. Soc. Psychol. 24: 285-290.

Dwyer, J., and Mayer, J. (1969). Psychological effects of variations in physical appearance during adolescence. Adolescence 3; 353-380.

Endler, N., and Magnusson, D. (1976). Toward an interactional psychology of personality. Psychol. Bull. 83: 956-974.

Garwood, S., and Allen, L. (1979). Self-concept and identified problem differences between pre- and postmenarcheal adolescents. J. Clin. Psychol. 35: 528-537.

Havighurst, R. J. (1953). Human Development and Education, Longmans and Green, New York.

Kleck, R., and Rubenstein, C. (1975). Physical attractiveness, perceived attitude similarity and interpersonal attraction in an opposite-sex encounter. J. Personal. Soc. Psychol. 31: $107-114$.

Langlois, J, and Stephan, C. (1977). Effects of physical attractiveness and ethnicity on children's behavioral attributions and peer preferences. Child Dev. 48: 1694-1698.

Latham, A. (1951). The relationship between pubertal status and leadership in junior high school boys. J. Genet. Psychol. 78: 185-194.

Lerner, R., and Gellert, E. (1969). Body build identification, preference, and aversion in children. Dev. Psychol. 1: 456-462.

Lerner, R., and Lerner, J. (1977). Effects of age, sex, and physical attractiveness on child peer relations, academic performance, and elementary school adjustment. Dev. Psychol. 13: 585-590.

Mathes, E., and Kahn, A. (1975). Physical attractiveness, happiness, neuroticism, and self-esteem. J. Psychol. 90: 27-30.

Miller, A. (1970). Role of physical attractiveness in impression formation. Psychon. Sci. 19: 241-243.

Pellegrini, R., Hicks, R., Meyers-Winston, S., and Antal, B. (1978). Physical attractiveness and self-disclosure in mixed-sex dyads. Psychol. Rec. 28: 509-516.

Petersen, A., and Taylor, B. (1980). The biological approach to adolescence: Biological change and psychological adaptation. In Adelson, J. (ed.), Handbook of Adolescent Psychology, John Wiley \& Sons, New York.

Richardson, S., and Royce, J. (1969). Race and physical handicap in children's preference for other children. Child Dev. 39: 467-480.

Rosenberg, M., and Simmons, R. G. (1971). Black and White Self-Esteem: The Urban School Child, Rose Monograph Series, American Sociological Association, Washington, D.C.

Simmons, R., Blyth, D., Van Cleave, E., and Bush, D. (1979). Entry into early adolescence: The impact of school structure, puberty, and early dating on self-esteem. Am. Sociol. Rev. 44: 948-967.

Simmons, R. G., Blyth, D. A., and McKinney, K. L. (1983). The social and psychological effects of puberty on white females. In Brooks-Gunn, J., and Petersen, A. (eds.), Girls at Puberty, Plenum, New York.

Snyder, M., Tanke, E., and Berscheid, E. (1977). Social perception and interpersonal behavior: On the self-fulfilling nature of social stereotypes. J. Personal. Soc. Psychol. 35: 656-666.

Staffieri, J. (1967). A study of social stereotypes of body-image in children. J. Personal. Soc. Psychol. 7: 101-104.

Walster, E., Aronson, V., Abrahams, D., and Rottman, L. (1966). Importance of physical attractiveness in dating behavior. J. Personal. Soc. Psychol. 4: 508-516.

Wilson, D. (1978). Helping-behavior and physical attractiveness. J. Soc. Psychol. 104: 313-314. 